\title{
An analysis of the Vietnamese system of occupational safety and health and setting priorities with the analytical hierarchy process
}

Department of Preventive Medicine and Community Health, University of Occupational and Environmental Health, Japan

S Matsuda

Correspondence to: Dr Shinya Matsuda, Department of Preventive Medicine and Community Health, University of Occupational and Environmental Health, Yahatanishi, Kitakyushu, 807, Japan.

Accepted 25 October 1995

Shinya Matsuda

\begin{abstract}
Objective-There were two objectives. The first was to describe the Vietnamese system of occupational safety and health (OSH) and its problems. The second was to evaluate priorities among future OSH policies by the analytical hierarchy process (AHP).

Methods-The Vietnamese OSH system was analysed in detail mainly based on various official documents. After the OSH problems in Vietnam were identified through discussions with Vietnamese OSH specialists they were given priorities in five different OSH policies, which were evaluated by the AHP.

Results and Conclusion-The OSH system in Vietnam is in theory well organised: the government has established fundamental laws and has organised the OSH administrative system from the central to the grassroots level. However, this system does not work sufficiently well to improve working conditions. According to discussions with Vietnamese OSH specialists, four factors associated with OSH problems in Vietnam were evaluated: shortage of materials and manpower, inadequate OSH information system, inappropriate OSH administrative system, and poor awareness of workers and employers about the OSH problems. Considering the relative importance of these four factors, the priorities within five policies were evaluated by the AHP technique. The results showed that the most important change needed was reorganisation of the OSH administrative system, followed by OSH education for workers and employers, training of personnel in OSH services, improvement of OSH research activity, and the establishment of an adequate OSH information system. It is expected that developed countries will help the Vietnamese government to implement these programmes.
\end{abstract}

(Occup Environ Med 1996;53:281-286)

Keywords: system of occupational safety and health; health policy; Vietnam; analytical hierarchy process

After the introduction of the new market policy so called "Doi Moi" in 1986, Vietnam has undergone a rapid economic development. The establishment of the new investment law facilitated investments from foreign countries, and many joint ventures have sprung up. By the end of 1994, there were 700 companies from 50 countries who have invested in about 1300 projects with a total registered capital of about 15 billion United States dollars. ${ }^{1}$ Economic development might improve the living standards of the Vietnamese people by providing various infrastructures that respond to basic human needs. However, because of the strong incentive to develop the economy rapidly, health problems tend to take second place. As a result, various health problems have emerged in the workplaces. Experiences in developed countries have shown that neglecting health problems will lead to severe consequences in the long term and that it is very difficult to repair the damage brought about by anarchic development. It is rather difficult for the Vietnamese government to implement sufficient programmes of occupational safety and health (OSH) to improve the current working conditions, because of the shortage of materials and human resources. Therefore, some international cooperative projects are expected to be organised in this field. However, before starting such programmes, it is necessary for non-Vietnamese advisors to obtain basic information about the Vietnamese $\mathrm{OSH}$ system and its problems. For this purpose, I was able to do four field studies in Vietnam (April and August 1994, March and May 1995). The first objective of this report is to describe the Vietnamese OSH system and its problems. The second objective is to evaluate the priorities of the future programmes to improve the working conditions in Vietnam.

\section{Methods}

\section{THE OSH SYSTEM IN VIETNAM}

\section{Administration}

Figure 1 shows the OSH administration system in Vietnam. Basically, four types of organisations are related to the $\mathrm{OSH}$ administration: the Ministry of Labour, the Ministry of Health, the Trade Union (Vietnam General Confederation of Labour: VGCL), and Ministries of particular industries (Ministry of Transportation, Ministry of Mining, etc). The Ministry of Labour is principally responsible for occupational safety. It promulgates various regulations about $\mathrm{OSH}$ matters and various safety standards in workplaces in collaboration with the Ministry of Health, and also conducts safety inspections. However, these inspections are not important enough to 


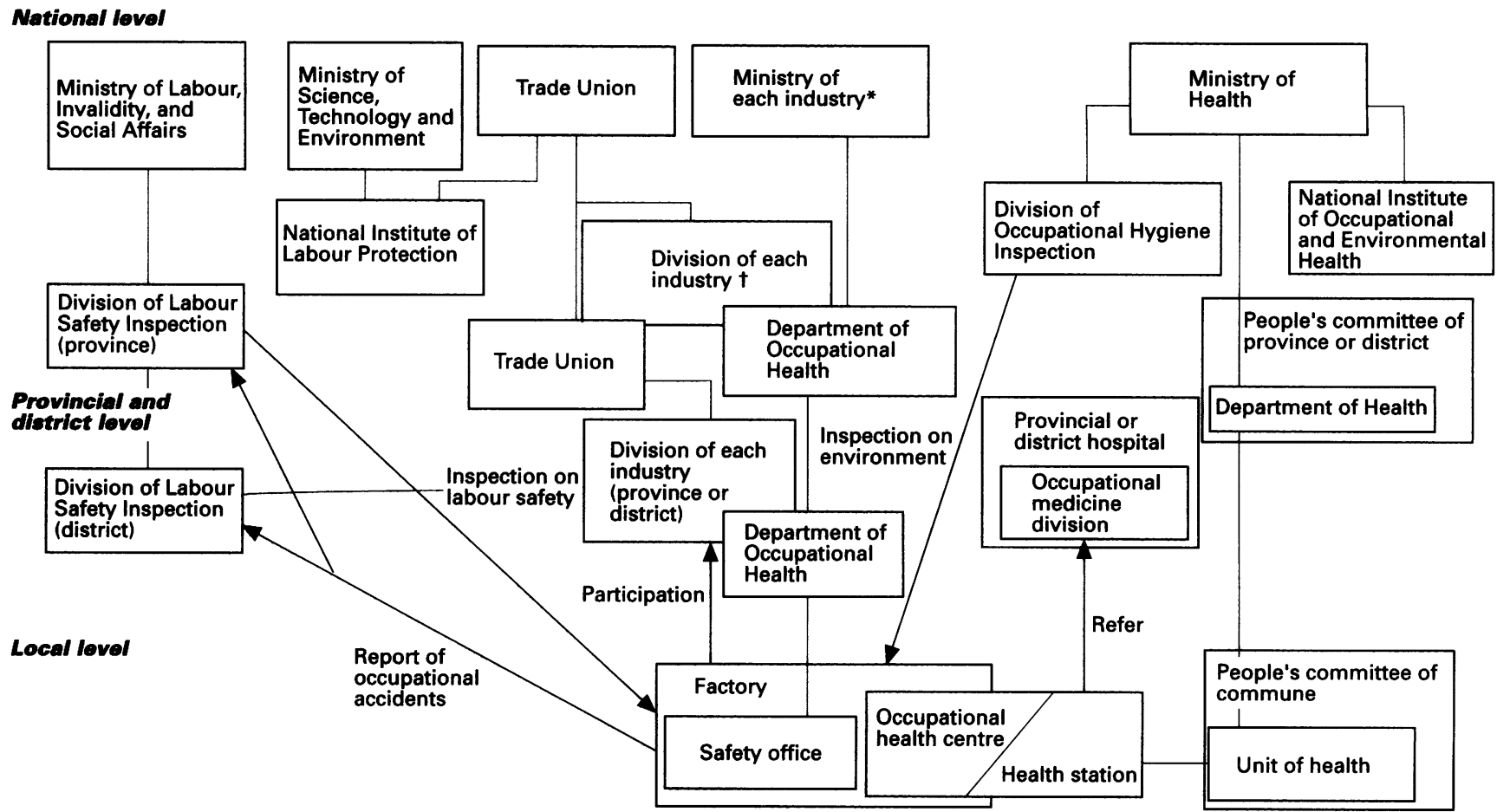

Figure 1 Administrative system of occupational safety and health in Vietnam. There exists a Department of Occupational Health under the ministry of each industry (transport, mining, etc). + There are 23 divisions at the national level.

improve the working conditions, mainly because of the shortage of manpower.

The Ministry of Health is concerned with occupational hygiene and health. It offers clinical services for the workers through its peripheral branches. Usually, there is a health station in each factory, where there are a few medical staff to offer clinical services-that is, periodical health check ups of the workers, general consultations, and first aid. If they find a suspected case of occupational disease, the case would be referred to the Division of Occupational Medicine in district or provincial hospitals, where specialists in occupational diseases work. The Ministry of Health also conducts environmental inspections in each factory, but there are insufficient materials and human resources to complete these.

The Vietnamese State set up several ministries responsible for particular industries, such as railways, mining, forestry, electricity, etc. Each ministry also organises its own branches responsible for OSH activities. The main purpose of these branches is to prevent occupational accidents and diseases.

The trade union also participates in $\mathrm{OSH}$ activities. Article 10 of the Constitution states that the function of a trade union is as follows: "The Trade Union, being the socio-political organisation of the working class, joints State organs, economic and social bodies in looking after and safeguarding the rights and interests of workers; it participates in State administration and social management, in the control and supervision of the activities of State organs and economic bodies; it educates workers to work well for national construction and defence."

The union organises a variety of $\mathrm{OSH}$ activ- ities that deal with occupational health and safety. It organises educational seminars on $\mathrm{OSH}$ issues and publishes periodicals in which OSH matters are often discussed. When a case of occupational disease or an occupational accident is reported, the union has a right to investigate it. Furthermore, the union acts as the representative of workers to protect the workers' health.

As a socialist country, the emphasis has been put on $\mathrm{OSH}$ activities. However, as the Vietnamese OSH administrative system is too fragmented, and each fragment has its own power structure, managerial efficiency is always questioned. Because information is rarely shared, quite often several ministries are doing the same thing at the same time. The lack of coordination among different departments is the most important weakness of the Vietnamese OSH administration system.

\section{Regulations}

There are two basic laws controlling $\mathrm{OSH}$ activities: the Constitution and the Labour Code.

The Constitution-Article 56 of the Constitution clarifies the responsibility of the State for occupational safety and health. It says, "The State shall enact policies and establish regulations for the protection of labour." Article 61 states the State's responsibility for the health protection of its citizens. It says: "The citizen is entitled to a regime of health protection."

The Labour Code-For duties of the State mentioned in the Constitution to materialise, the government enacted the Ordinance of Labour Protection in 1992. This ordinance has been included in the new Labour Code 
Table 1 Official statistics of occupational diseases and accidents

\begin{tabular}{lr}
\hline Occupational diseases (cumulative number up to the end of 1994): & 6507 \\
Silicosis & 1 \\
Asbestosis & 13 \\
Tuberculosis (occupational) & 840 \\
Noise-induced hearing loss & 60 \\
Lead poisoning & 6 \\
Mercury poisoning & 68 \\
Others & 7495 \\
Total & \\
Occupational accidents (in 1993): & 212 \\
Fatal accidents (n) & 231 \\
Deceased workers (n) &
\end{tabular}

Source: National Institute of Labour Protection (1994).

and related decrees since 1994. In this Code, chapter IX (articles 95-108) is allocated to OSH activities. Article 95 defines four groups in charge of OSH activities: employers, employees, the State, and the Vietnam General Federation of Labour (trade union). Article 96 states that the Ministry of Labour and the Ministry of Health are responsible for establishing a list of machines, equipment, materials, and substances which may damage workers' health. Article 97 mentions the responsibility of employers to comply with the environmental standards in the workplace and to conduct a periodic measurement of environment. Article 99 clarifies the right of workers to refuse to work or to leave their work place when the working conditions are apparently dangerous. Article 101 and 102 define the duties of employers to protect workers' health. They have to supply personal protective equipment for workers, to organise $\mathrm{OSH}$ training seminars, to inform workers of $\mathrm{OSH}$ regulations, and to organise a periodic health check up. Employers have to pay for these services. Articles 105-108 are related to occupational accidents and occupational diseases. If a worker becomes a victim of an occupational accident or disease, he has a right to receive compensation. To manage this compensation system, the State has had a social security scheme since January 1995. In this scheme, an employer has to pay the equivalent of $15 \%$ of the total salary of each worker, and a worker also has to contribute $5 \%$ of his salary to the fund. There is no differentiation between workers' compensation and medical care insurance, that is, the fund assures compensation for all occupational accidents and diseases, assistance for medical expenditures, retirement pension, and death compensation.

Other regulations-As well as the two basic regulations already mentioned, there are other legal documents about OSH matters.

(1) Article 34 in the Law on Foreign Investments in Vietnam defines the investor's responsibility regarding environmental protection.

(2) Article 4 in the Ordinance on Foreign Technology Transfer in Vietnam clarifies the obligation of the owner of a factory to ensure the safety and environmental protection.

(3) The Law on Public Health Protection has a variety of articles defining the rights and duties of citizens, public organisations, and enterprises to ensure occupational safety and health at workplaces (articles 1, 4, 9, 10, 12, 14 , and 18).
(4) The Law on Environmental Protection defines that environmental protection should always be considered when importing and exporting technology, machinery and equipment (articles 19 and 29). Although the Vietnamese government has established many $\mathrm{OSH}$ regulations, these are not adequately obeyed. There are many reasons for this: the lack of a uniform system among different regulations, inadequate dissemination of regulations for the public, low awareness of employers for OSH matters, and others.

\section{OSH statistics}

As the OSH information system has not been adequately implemented in Vietnam, the availability of data is very limited. Table 1 shows the national data of occupational diseases and occupational accidents. At the end of 1994, there were 7495 cases of occupational diseases registered at the national level..$^{2}$ Among them, silicosis was the most serious (6507 cases: $86.8 \%$ ), followed by noise induced hearing loss ( 840 cases: $11 \cdot 2 \%$ ). Among the cases of silicosis, $28.7 \%$ were workers in coal mines, of which $70 \%$ were working underground. ${ }^{3}$ So far as occupational accidents are concerned, it is estimated that 200 to 300 fatal occupational accidents and around 20000 injuries occur annually. Apparently, these statistics were underreported. For example, according to the results of a sample survey in 48 factories employing 3150 workers, conducted by Thung and Trinh, the rate of occupational accidents was 17.6 per 1000 workers and the prevalence of occupational diseases was $6 \cdot 7 .{ }^{4}$ When considering that their study was based on data from relatively large factories, the real situation must be rather worse.

EVALUATION OF PRIORITIES AMONG THE FUTURE OSH POLICIES IN VIETNAM

Studied population and methods

As a result of discussions with several OSH specialists in Vietnam during my first two visits, I structured the $\mathrm{OSH}$ problem factors in Vietnam and strategies to solve them (fig 2). Four factors associated with the $\mathrm{OSH}$ problems in Vietnam were evaluated: shortage of materials and manpower, inadequate $\mathrm{OSH}$ information system, inappropriate $\mathrm{OSH}$ administrative system, and low awareness of workers and employers of OSH problems. To solve these problems, the following five strategies were considered: training of personnel in OSH services, reorganisation of $\mathrm{OSH}$ administrative system, OSH education for workers and employers, establishment of an adequate $\mathrm{OSH}$ information system, and improvement of $\mathrm{OSH}$ research activities. After evaluating the validity of this scheme through discussions with Vietnamese OSH specialists, I tried with AHP to evaluate the priorities of these five strategies. ${ }^{5}$

Population studied - On my third stay in Hanoi, we organised a seminar on occupational safety and health at the National Institute of Labour Protection, Hanoi. There were about 40 participants in this seminar from the National Institute of Labour Protection, Hanoi Medical College, Ministries, and other insti- 
Figure 2 Structure of problems of occupational safety and health in Vietnam.

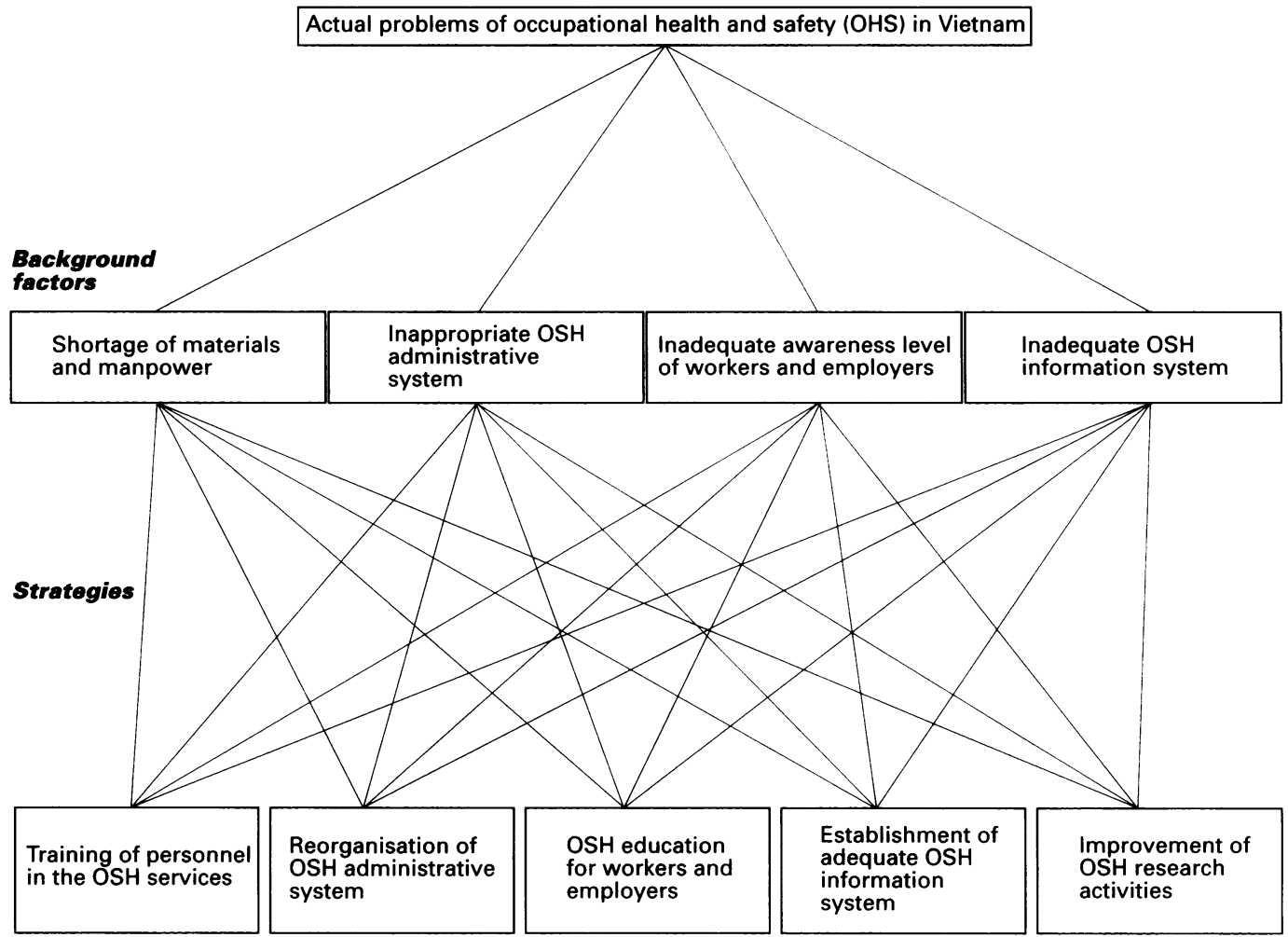

of the hierarchy of problems are measured with respect to the elements of the next higher level. This is done by means of pairwise comparisons of alternatives to indicate the strength with which one alternative dominates another for the criterion by which they are compared. Mathematically, the problem is to solve a homogeneous linear equation. The application of the concept of pairwise comparison and the procedure for adopting priorities was as follows. In the model structured, $\mathbf{n}$ strategies are given, $A_{1}, \ldots, A_{n}$, whose values of importance $w_{1}, \ldots, w_{n}$ measured by several criteria, are known. Here, consider the matrix A of pairwise ratios whose rows give the ratios of the values of importance of each alternative with respect to all others and then multiply it on the right by the vector of values of importance w. Figure 3 shows the result of this multiplication. Thus, to recover the scale from the matrix of ratios we must solve the problem $\mathrm{Aw}=\mathrm{nw}$. It has a non-trivial solution only if the determinant of $(A-n I)$ vanishes-that is, $n$ is an eigenvalue of $A$. In practice, we cannot give the precise values $w_{i} / w_{i}$ but only estimates of them; $\mathrm{A}^{\prime}$ (comparison matrix). Thus, the problem becomes $\mathrm{A}^{\prime} \mathrm{w}^{\prime}=$ $1_{\max } \mathrm{w}^{\prime}$, where lmax is the largest or principal eigenvalue of $\mathrm{A}^{\prime}$. It has been shown that the eigenvector corresponding to the largest eigenvalue of the matrix provides the relative priorities of the factors, and preserves ordinal preferences among the alternatives. ${ }^{5}$ Thus, from the matrix it is possible to form for paired comparisons a vector of weights $\left(w^{\prime}\right)$ which reflects the relative importance. In the present study, each participant was required to choose one of three answers to construct the pairwise comparison matrix as follows; if $A_{i}$ is more important than $A_{i}$ then $w_{i} / w_{j}=2, A_{i}$ is as important as $A_{j}$ then $w_{i} / w_{i}=1, A_{i}$ is less impor$\operatorname{tant}$ than $A_{j}$ then $w_{i} / w_{j}=1 / 2$. In practice, at the

\begin{tabular}{llllll} 
Table 2 & \multicolumn{5}{c}{ Comparison of factors associated with OSH problems in Vietnam } \\
\hline & $F 1$ & $F 2$ & $F 3$ & $F 4$ & Priorities \\
\hline F1 & 1.00 & 1.53 & 0.73 & 1.17 & 0.26 \\
F2 & & 1.00 & 0.73 & 0.88 & 0.20 \\
F3 & & & 1.00 & 1.57 & 0.32 \\
F4 & & & & 1.00 & 0.22 \\
\hline
\end{tabular}

$\mathrm{F} 1=$ shortage of materials and manpower; $\mathrm{F} 2=$ inappropriate $\mathrm{OSH}$ administrative system; F3 inadequate awareness of workers and employers; F4 = inadequate OSH information system. 
Table 3 Comparison of strategies to overcome the factors associated with OSH problems in Vietnam

\begin{tabular}{|c|c|c|c|c|c|c|c|c|c|c|c|c|}
\hline & \multicolumn{6}{|c|}{ Shortage of materials and manpower } & \multicolumn{6}{|c|}{ Inappropriate OSH administrative system } \\
\hline & $S 1$ & $S 2$ & $S 3$ & $S 4$ & $S 5$ & Prionities & $S 1$ & $S 2$ & $S 3$ & $S 4$ & $S 5$ & Priorities \\
\hline \multirow[t]{3}{*}{$\begin{array}{l}\text { S1 } \\
\text { S2 } \\
\text { S3 } \\
\text { S4 } \\
\text { S5 }\end{array}$} & $1 \cdot 00$ & $\begin{array}{l}0.85 \\
1.00\end{array}$ & $\begin{array}{l}1.00 \\
1.34 \\
1.00\end{array}$ & $\begin{array}{l}1.66 \\
1.41 \\
1.45 \\
1.00\end{array}$ & $\begin{array}{l}0.90 \\
1.11 \\
1.05 \\
0.90 \\
1.00\end{array}$ & $\begin{array}{l}0 \cdot 21 \\
0 \cdot 24 \\
0 \cdot 20 \\
0 \cdot 15 \\
0 \cdot 20\end{array}$ & $1 \cdot 00$ & $\begin{array}{l}0.59 \\
1.00\end{array}$ & $\begin{array}{l}1.03 \\
1.80 \\
1.00\end{array}$ & $\begin{array}{l}0.92 \\
1.53 \\
1.41 \\
1.00\end{array}$ & $\begin{array}{l}1.08 \\
1.41 \\
1.14 \\
1.14 \\
1.00\end{array}$ & $\begin{array}{l}0.17 \\
0.29 \\
0 \cdot 19 \\
0 \cdot 18 \\
0 \cdot 17\end{array}$ \\
\hline & \multicolumn{6}{|c|}{ Inadequate awareness of workers and employers } & \multicolumn{6}{|c|}{ Inadequate OSH information system } \\
\hline & $S 1$ & $S 2$ & $S 3$ & $S 4$ & $S 5$ & Priorities & $S 1$ & $S 2$ & $S 3$ & $S 4$ & $S 5$ & Priorities \\
\hline $\begin{array}{l}\text { S1 } \\
\text { S2 } \\
\text { S3 } \\
\text { S4 } \\
\text { S5 }\end{array}$ & $1 \cdot 00$ & $\begin{array}{l}0.60 \\
1.00\end{array}$ & $\begin{array}{l}0 \cdot 81 \\
1 \cdot 14 \\
1 \cdot 00\end{array}$ & $\begin{array}{l}1 \cdot 21 \\
1.34 \\
1.62 \\
1.00\end{array}$ & $\begin{array}{l}1.21 \\
1.41 \\
1.34 \\
1.00 \\
1.00\end{array}$ & $\begin{array}{l}0.18 \\
0.25 \\
0.23 \\
0.16 \\
0.17\end{array}$ & $1 \cdot 00$ & $\begin{array}{l}0.62 \\
1.00\end{array}$ & $\begin{array}{l}1.31 \\
1.62 \\
1.00\end{array}$ & $\begin{array}{l}0.69 \\
0.83 \\
0.73 \\
1.00\end{array}$ & $\begin{array}{l}0.79 \\
1.00 \\
0.83 \\
1.45 \\
1.00\end{array}$ & $\begin{array}{l}0.17 \\
0.23 \\
0.15 \\
0 \cdot 25 \\
0.20\end{array}$ \\
\hline
\end{tabular}

$\mathrm{S} 1$ = training of personnel in the OSH services; $\mathrm{S} 2$ = reorganisation of the OSH administrative system; $\mathrm{S} 3=$ the OSH education for workers and employers; S4 = establishment of adequate $\mathrm{OSH}$ information system; $\mathrm{S} 5=$ improvement of $\mathrm{OSH}$ research activities.

first level, four factors were compared with each other for their relative importance. Then, the five strategies were compared with each other for their relative usefulness to cope with each of the four problem factors already mentioned. For example, the question is as follows: to improve the problem related to the shortage of materials and manpower, which strategy is the most important, "training of personnel in the OSH services" or "reorganisation of the OSH administrative system?" Participants were required to answer all statements of comparison in a questionnaire method. Then, to obtain each value of the components in the pairwise comparison matrix, the geometric mean of the answers of 30 participants was calculated, according to the recommendation of Saaty and Vargas. ${ }^{5}$

\section{Results}

Table 2 shows weights of each problem calculated by the comparison matrix. A low awareness of employers and workers about $\mathrm{OSH}$ problems was detected as the most important problem, followed by a shortage of materials and manpower, an inadequate $\mathrm{OSH}$ information system, and an inappropriate $\mathrm{OSH}$ administrative system.

Table 3 shows the matrix of weights which represent the relative importance of each strategy in solving these problems. For example, to solve the problem of low consciousness of employers and workers about OSH problems, reorganisation of the OSH administrative system was evaluated as the most effective remedy, followed by the other four strategies, $\mathrm{OSH}$ education of workers and employers, improvement of research activity in the field of

Table 4 Composite priorities to solve OSH problems in Vietnam

\begin{tabular}{llllll}
\hline & $F 1$ & $F 2$ & $F 3$ & $F 4$ & $\begin{array}{l}\text { Composite } \\
\text { priorities }\end{array}$ \\
\hline S1 & 0.26 & 0.20 & 0.32 & $0 \cdot 22$ & $0 \cdot 18$ \\
S2 & 0.21 & $0 \cdot 17$ & $0 \cdot 18$ & $0 \cdot 17$ & $0 \cdot 25$ \\
S3 & $0 \cdot 24$ & $0 \cdot 29$ & $0 \cdot 25$ & $0 \cdot 23$ & $0 \cdot 20$ \\
S4 & $0 \cdot 20$ & $0 \cdot 19$ & $0 \cdot 23$ & $0 \cdot 15$ & $0 \cdot 18$ \\
S5 & $0 \cdot 15$ & $0 \cdot 18$ & $0 \cdot 16$ & $0 \cdot 25$ & $0 \cdot 18$ \\
\hline
\end{tabular}

$\overline{\mathrm{F} 1}=$ shortage of materials and manpower; $\mathrm{F} 2$ = inappropriate $\mathrm{OSH}$ administrative system; F3 = inadequate awareness level of workers and employers; F4 = inadequate OSH information F3 = inadequate awareness level of workers and employers; F4 = inadequate OSH information
system; S1 = training of personnel in the OSH services; S2 = reorganisation of the OSH system; $S 1=$ training of personnel in the OSH services; S2 = reorganisation of the OSH
administrative system; $S 3=$ the OSH education for workers and employers; S4 = establishment administrative system; $\mathrm{S} 3=$ the $\mathrm{OSH}$ education for workers and employers; $\mathrm{S4}=$ estabition
of adequate OSH information system; S5 $=$ improvement of $\mathrm{OSH}$ research activities.
$\mathrm{OSH}$, and establishment of an adequate information system.

Table 4 shows the relative importance of the five strategies calculated by the AHP method. Reorganisation of the OSH administrative system was considered to be the most important strategy to improve $\mathrm{OSH}$ conditions in Vietnam. This strategy was followed by education of workers and employers about $\mathrm{OSH}$, training of personnel, improvement of research activities in the field of $\mathrm{OSH}$, and establishment of an adequate information system.

\section{Discussion}

AHP METHOD

In this analysis, I used the AHP method to evaluate the priorities among possible strategies for the improvement of OSH conditions in Vietnam. The AHP method has been applied to various political issues to assess priorities among different strategies. ${ }^{5}$ Although this method is very useful to summarise the opinion of experts on studied subjects, one must be cautious when interpreting the results. The most important problem is that the structured model is heavily influenced by how the investigator has evaluated the problem. This perceptive process is apt to be heavily influenced by the interest of the investigator as well as by his capacity to properly formulate the problem. Another important problem is that the results will vary according to the characteristics of members in the studied group. For example, there may be a difference in priorities between medical doctors specialising in occupational diseases and governmental clerks engaged in labour inspections. In this sense, the present results may be favourable to researchers and administrators in the OSH field, because of the composition of members in the group. Therefore, the present results cannot be regarded as definitive ones. However, it should be noted that the planning must be a continuous process and not a one point activity. I think that it is important to continue this type of discussion to obtain a concrete direction for future policies. 
well organised. The government has established fundamental laws for OSH matters and has organised the $\mathrm{OSH}$ system from the central to the grassroots level. To make this system work adequately, it is necessary to have the political tools such as information, inspection activities, and penalties enforced by law. In the current situation, however, there is no adequate $\mathrm{OSH}$ information system and no adequate inspection activities, with the result that penalties defined in the law are rarely applied. There are many reasons for this situation. The shortage of manpower and materials and inadequate awareness of workers and employers due to the strong incentives for economic development are two of them.

The complicated OSH administrative system (fig 1), makes the situation worse. Because different administrative bodies are insular, information is rarely shared, and the duplication of programmes also occurs. Under the current situation, where there is a severe shortage of human and financial resources for $\mathrm{OSH}$ activities, this kind of duplication causes a great waste of time and resources. It is, therefore, strongly recommended that the Vietnamese government reorganises the $\mathrm{OSH}$ administrative system. Also, in the present AHP analysis, the realisation of reorganisation of the administrative system was evaluated by participants as the most important strategy to solve various $\mathrm{OSH}$ problems. However, it is the most difficult task to be realised in the short term, because the reorganisation of the system is too much of a political issue.

According to the results of AHP analysis, the education of employers and workers was evaluated as the second most important strategy. After the introduction of a new market policy, the incentive for higher productivity has become very strong among workers and employers. Thus, OSH problems have reverted to second place. For example, in our previous study, $60 \%$ of workers replied that they would accept hazardous working conditions to earn more money, and $30 \%$ of the workers studied accepted the fact of child labour (unpublished data). In fact, I found many cases of child labour in family managed small factories in Hochiminh City. Education is the most important strategy to solve these problems at the local level. Especially strate- gies with worker participation as recommended by the International Labour Organisation seem to be most suitable to enlighten workers and employers about the importance of OSH matters. It has been reported that this type of strategy has been very useful in improving working conditions in developing countries. ${ }^{6}$ As the Labour Code of Vietnam clarifies the role of the trade union in $\mathrm{OSH}$ activities, this strategy of worker participation will be suitable and effective.

Finally, to improve working conditions in Vietnam, one must know the actual situation more precisely. Currently, it is impossible to introduce a nationwide $\mathrm{OSH}$ information system within the next few years. Therefore, research activities will be very important in studying the situation. It is especially necessary to organise epidemiological research and environmental measurement studies. There are many Vietnamese OSH researchers, but their knowledge and skills are old fashioned, because of the lack of up to date information. Furthermore, they lack the financial resources and materials to conduct research both in laboratories and in the field. I think that assistance in the field of research is the most timely target for international cooperative programmes. Through the collaborative research programmes, we shall be able to share knowledge and skills, and shall be able to train personnel in this field. It is expected that several $\mathrm{OSH}$ research programmes will be incorporated into the international cooperative programmes in Vietnam.

This study was supported by the Nissan Science Foundation. I am very grateful to Professor Nguyen An Luong (Director of NILP, Vietnam) for his kind cooperation in this study.

1 Luong NA. Occupational safety and health issues in transfer of technology and foreign investment in Vietnam. In: Proceedings of the National Workshop on Occupational Safety and Health in Transfer of Technology and Foreign Investment in Vietnam. Hanoi: NILP, 1995:1-16.

2 Data of National Institute of Labour Protection. Hanoi: NILP, 1994.

3 Hoai NV. The silicosis at coal-mining industry in technology transfer. In: Proceedings of the National Workshop on Occupational Safety and Health in Transfer of Technology and Foreign Investment in Vietnam. Hanoi: NILP, 1995.

4 Thung D, Trinh LV. Assessment of pollution of the working environment in Vietnam and a general solution. Hanoi: environment in Vietnam and a general solution.

5 Saaty TL, Vargas LG. Prediction, projection, and forecasting. Massachusetts: Kluwer Academic, 1991.

6 Kogi K, Phoon WO, Thurman E. Low-cost ways of improving working conditions: 100 examples from Asia. Geneva: International Labour Organisation, 1989. 